\title{
Natural resistance and breeding capacity of cows under low doses of radiation
}

\author{
V. Slavov, \\ Professor, Corresponding Member of the National Academy of Sciences \\ doctor of agricultural sciences, \\ Zhytomyr National Agroecological University \\ T. Plotko, \\ nstitute of Animal Breeding and Genetics named after M.V. Zubets NAAS
}

The purpose. To study state of natural resistance and breeding capacity of cattle in conditions of moderate chronic radioactive irradiation in the remote period after Chernobyl disaster. Methods. Radiological probes are carried out of surface contamination of animals, milk, litter, feedstuffs, water as well as clinical-and-gynecologic examination of cows. Duration of independence-, service- and betweenpregnancy periods is specified. Biochemical and hematological indexes of blood are studied. Results. At animals delivered from "clean" zone and grown in radioactively contaminated area in due course the amount of erythrocytes is diminished. Indexes of the leukocytic blood count at animals from "low-purity" zone were within the limits of norm, with offset to minimum values. Conclusions. At animals grown under the influence of radiation effect of small intensity indexes of blood are on lower limit of norm. Adult animals delivered in zone of radioactive impurity are more stress resistant as compared to aboriginal ones, but in the course of time this variance almost peters. Animals grown in "low-purity" zone were unhealthier, more often and longer were ill with various forms of endometritis and mastitis.

Key words: cattle, ionizing irradiation, natural resistance, breeding capacity.

The increased radiation background in large areas of Ukraine, formed as a result of the Chernobyl accident in 1986, caused the need for additional biological research in the study of the influence of low levels of ionizing radiation on living organisms. The danger of further anthropogenic pollution of the environment has raised the problem of finding methods for indicating this process [1].

The consequences of an industrial disaster at the Chornobyl Nuclear Power Plant (ChNPP) do not have global analogues [2]. Under field conditions, a test ground for studies on the long-term effects of low levels of radiation on biological objects has been created. Small doses of irradiated radionuclides, lack of linear dependence in a certain range of levels; chronic irradiation with high biological efficacy; the variety of environmental factors, the physiological state of the organism can greatly change the radiation effect [3-6] this is far from a complete list of factors of direct and indirect effects of radiation on the physiological status of the organism with its age characteristics. The large-scale problem of long-term chronic exposure of animals in contaminated areas and the long-term consequences of this impact require further research. In modeling experiments, the main objects for research are laboratory animals. However, the problem of adaptation and breeding of farm animals [8], which is directly held in zones with different radionuclide pollution and influence of internal and external radiation, is actual.

The purpose of the research is to study the state of natural resistance and reproductive ability of bovine animals in conditions of moderate chronic radioactive exposure in the remote period after the Chernobyl accident.

Materials and methods of research. The research was conducted at LLC "Obriy" of Ivankivsky district of the Kyiv region during 2004-2007 on cows of Ukrainian black-and-white milk breed. The effect of longterm exposure of small doses of radiation on hematological and immunobiological parameters of blood of 
cows in the comparative aspect was studied. To this end, in 2004, non-livestock of Ukrainian black beetroot breed from the breeder's breeding farm "Niva" of the Yampil district of the Vinnytsia region (Besovednoye) was introduced into the farm.

It was formed 2 groups of cows on the principle of par-analogues. The first group (group I - "clean zone") consisted of imported animals, the second (group II - "dirty zone") - cows grown in local conditions. We studied adaptation to new climatic and technological conditions of use and maintenance in conditions of long-term exposure radiation of low intensity. At the beginning of the study, all the animals were clinically healthy.

To assess the radiological conditions for the keeping of experimental animals in selected farms, indicators of the level of agricultural land contamination, the intensity of the exposure dose (total gamma background) in livestock buildings, on wands and pastures, as well as radionuclide contamination of the main feeds were used. The radionuclide contamination of agricultural lands was determined by the calculation and the method of analysis reference materials of the national dosimetric certification of settlements exposed to radioactive contamination udnennya. Determination of the total gamma-background of air at separate objects of the economy was carried out using a dosimeter-radiometer SRP-88-01, specific radioactivity of feeds on the contents of $137 \mathrm{Cs}$ - a radiometer RGG- "Adani" in accordance with "Methods of complex radiation inspection of contaminated fodders as a result of the Chornobyl catastrophe"

The influence of factors influencing the manifestation of the adaptive capacity of the body was studied by examining the hematological and immunological parameters of the blood [8, 9]. For this purpose, according to generally accepted methods, the content of leukocytes and erythrocytes in $1 \mathrm{~mm} 3$ of blood, the count of the leukocyte formula and the eosinophilic test were determined. In conducting biochemical blood tests, total protein, carotene, calcium, inorganic phosphorus, reserve alkalinity were determined. Covers were examined on a hidden mastitis (using a mastin test), and endometritis

\section{Research results and their discussion.}

The conducted four-year haematological studies have shown that in animals that have been grown and constantly kept in the radioactive zone and brought from the "clean" zone over time there is a decrease in the number of erythrocytes in 2004 in group I from $6.82 \pm 0.10$ to $6.42 \pm 0.03$ in 2007, or $6 \%$, in animals of the second group, respectively, $6.04 \pm 0.06,5.94 \pm 0.08$, or $1.7 \%$. It should be noted that the rate of reduction of the number of erythrocytes in imported animals is higher compared to animals grown under conditions of radiation pollution. The amount of leukocytes during the years of research in animals of group I complied with the norms, and in the dynamics decreases from 7,01 $\pm 0,06$ in 2004, to $6.8 \pm 0.06$ in 2007. In animals that were constantly in such conditions, this figure practically remains at one level $(7,03 \pm 0,09$ and $7,12 \pm 0,05$, respectively).

In studying the leukocyte blood formula, it has been established: in animals of group I (the "clean" zone), for four years of research, an increase in basophils was observed at $10 \%(0.3 \pm 0.11$ in 2004 and $0.33 \pm$ 0.11 in 2007); In animals of group II ("polluted" zone) minor fluctuations were observed within the limits of $0,35 \pm 0,11-0,41 \pm 0,12$. In animals of group I ("pure" zone) there is a decrease in eosinophils during observations - by $4.4 \%$ (from $6.2 \pm 0.17$ in 2004 to $5.8 \pm 0.09$ in 2007) in animals of group II (" contaminated "zone) there were fluctuations within the range of $5.24 \pm 0.22$ (in 2006) - $5.65 \pm 0.17$ (in 2005). In animals of both groups throughout the experiment there is a "shift" of neutrophils to the left, with an increase in their total number (all forms) in animals of group I ("clean" zone) by $18.3 \%$, and amounted to $5.83 \pm 0$ in 2007,23 against $4.9 \pm 0.23$ in 2004. In animals of group II ("polluted" zone) the growth was $7.6 \%$ and was, accordingly, $7.85 \pm 0.2$ and $6.8 \pm 0.30$. In the case of certain types of neutrophils in animals of group I ("clean" zone) young forms appear in a small number for the second year of being in the zone of radioactive contamination, their number increases with each year and in 2007 makes $1.22 \%$. In animals of group II ("polluted" zone) fluctuations in the range of $1.38 \pm 0.14$ (in 2007) were noted $-2.15 \pm 0.49$ (in 2004).

The content of lymphocytes in both groups during the years of research decreased. In animals of group I ("clean" zone) decreased by $6.12 \%$, in animals of group II ("polluted" zone) by $3.7 \%$. The difference between the content of lymphocytes of groups I and II at the beginning of the trial was $5.8 \%$, at the end of the 
experiment $-4.06 \%$. Also, monocytes in both groups decreased. It should be noted that in animals of group II ("polluted" zone), basophils were more than $0.1 \%$ throughout the time of research than in animals of group I ("clean" zone). Monocytes in animals of both groups had minor fluctuations in years and were within the limits of physiological norms. In animals of group I ("pure" zone) the amount of monocytes during research decreased by $7,14 \%$ (from $7 \%$ in 2004 to $6.5 \%$ in 2007). In animals of group II ("polluted" zone), the amount of monocytes during research decreased by $3.08 \%$ (from $6.5 \%$ in 2004 to $6.3 \%$ in 2007).

Stress resistance of the body is important in the adaptation of animals to the conditions of maintenance and use. Stress resistance was determined by an eosinophilic test (Table 1).

\section{The content of eosinophils in $\mathrm{mm}^{3}$}

\begin{tabular}{|l|l|l|l|l|}
\hline \multirow{2}{*}{ Year } & \multicolumn{2}{|c|}{ Group I ("clean" zone) } & \multicolumn{2}{c|}{ Group II ("polluted" zone) } \\
\cline { 2 - 5 } & $\mathbf{n}$ & $\mathbf{M} \pm \mathbf{m}$ & $\mathbf{n}$ & $\mathbf{M} \mathbf{m}$ \\
\hline 2004 & 20 & $458,6 \pm 13,32$ & 20 & $430,65 \pm 9,37$ \\
\hline 2005 & 19 & $445,84 \pm 8,33$ & 17 & $430,88 \pm 5,29$ \\
\hline 2006 & 19 & $428,63 \pm 8,41$ & 17 & $425,35 \pm 5,08$ \\
\hline 2007 & 18 & $414,78 \pm 8,32$ & 13 & $412,85 \pm 6,08$ \\
\hline
\end{tabular}

The study of stress-resistant animals showed that at the beginning of the experiment, stress-resistant animals in the first and second groups were almost identical (12 and 11 respectively), then at the end of the experiment in the first group 13 were found in the second 7 head. The data in Table 1 indicate that in both groups the number of eosinophils has decreased over the years and has almost identical parameters:

414.78 in the first group, and 412.85 cells in $\mathrm{mm} 3$ in the second. It should be noted that the level of eosinophils in cows from the "clean" zone (group I) was $458.6 \pm 13.32 \mathrm{in} \mathrm{mm} 3$ of blood, and animals in group II ("contaminated" zone) were below $430.65 \pm 9,37$ at the beginning of the study. It should be noted that during the studies in the first group 2 heads were eliminated, in the second one -7 . This suggests the benefit of the assumption that the prolonged occurrence of animals under the influence of radiation pressure negatively affects the defenses of the organism, a decrease of about $10 \%$ of the level of eosinophils, from the average of the flock, may be "critical" for further economic use.

Regarding the biochemical picture of blood of animals in both groups, the total protein was within the normal range, but had a decrease in the first group of $9,76 \%$, in the second to $10 \%$, the Lower reserve in animals of the first group decreased by $7,69 \%$, calcium and phosphorus by 7,14 and $11.63 \%$ respectively. During the first year of the experiment, carotene in animals of the first group decreased sharply (by $44.74 \%$ ), and in the third year, it equaled the indicators of the second group. At the end of the experiment, the reduction was $63.16 \%$ of the baseline.

Resistance - is closely related to the reproductive capacity of the animal organism. Therefore, in our studies, we monitored the changes in the reproductive system and reproductive capacity of cows while keeping them in radioactive contaminated conditions of low intensity.

Animals of both groups first settled at the age of 661-667 days, the age of fertile inseminating 661-670 days

All animals of group I became pregnant after the first insemination. The smallest age of the first insemination was 654 days, the largest - 670 days. In animals of group II, which were naturally exposed to small doses of irradiation, the youngest age of the first inflorescence was 624 days, the largest - 692 days, but the animals of the second group, whose age at the first insemination was less than 22 months inseminated a second time. The term of fertile insemination in them increased by 16,5 $\pm 3,12$ days. During pregnancy the animals did not suffer from infectious and other diseases. The data of the course of the genera, which was evaluated for [78], is shown in Figure 1 


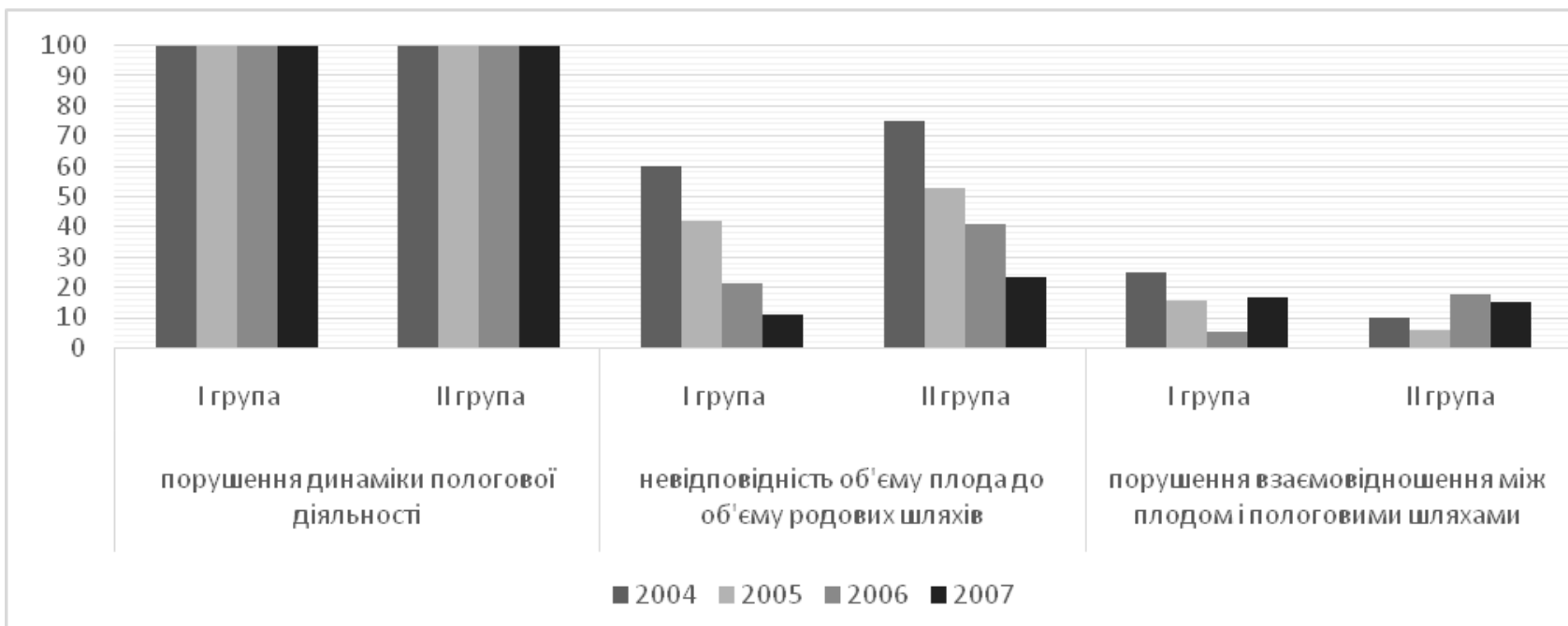

Fig. 1 Flow of the genera of experimental animals, \%

Throughout the research period, all the animals of both groups were provided with maternity care $(100 \%)$. Inconsistencies in the volume of the fetus to the volume of the birth canals were recorded at 60 beds, which is almost $42 \%(41.96 \%)$. In animals of group II ("contaminated" zone) - 34 cases $(50.7 \%$ of all lodges, in animals of group I ("clean" zone) - 26 cases, which makes up $34.2 \%$, that is, the animals of the second group were worse adapted to Reproduction (narrow the internal volume of the pelvis) The violation of the relationship between the fetus and the childbirth pathways during the entire period of research did not differ, and on average they comprised $15.79 \%$ in the first group, $11.94 \%$ in the second, as in animals imported from the "pure" zone, and in animals grown under conditions of radiation pressure on the first calving, the greatest complication occurred In the cows with the second calving of complications of labor activity in the first group was $57.89 \%$ ( 11 cases), in the second $58.82 \%$ (10 cases) .In the third calving, respectively $-26.32 \%$ (5 cases) and $58.82 \%$ ( 10 cases), the fourth, respectively, $27.77 \%$ ( 5 cases) and $38.46 \%$ ( 5 cases).

Delay of lactation, pathology of the third stage of labor, in the firstborn was diagnosed in $10 \%$ of animals in each group. On average, during the years of research in cows of group I ("clean" zone), $11.8 \%$ of animals had a delay in lactation, with fluctuations of $5.3 \%$ in2006. to $16,6 \%$ in 2007 ; in cows of group II ("polluted" zone) $-16.4 \%$, with fluctuations from $10 \%$ in 2004. to $23,1 \%$ in 2007 Generally, animals of group II ("polluted" zone) had $4.6 \%$ of cases of delayed litter more than animals of group I ("clean" zone) and exceeded them in 2005-2007. by $1.9,12.4,6.5 \%$, respectively. The immediate causes of placental delay are the intensity of sequential reversal and involution of the uterus, the growth of parts of the placenta due to inflammatory processes in the endometrium or in the chorionic fetuses. After genera, the general resistance of the organism and, in particular, the organs of the reproductive system, which promotes the development of various animal diseases, is greatly reduced in the background of excessive contamination of the birth canal during childbirth. The state of the genital organs of cows, which did not show "hunting" during 45 days, were studied by the method of clinical and gynecological research according to the generally accepted method.

They also evaluated the hormonal state of the body of females, in which no more than 45 days after calving were detected hunting, through cytological studies of smears of the mucous membrane of the vagina. In these animals, estrogen deficiency was detected.

A retrospective study found that the main reason for a long post-end period is uterine subunvulation in both groups. Cytological examination of vaginal mucous membranes revealed significant estrogen deficiency. The hidden mastitis and endometritis were found in animals of both groups. The mastitis examined all animals in the first, third and sixth months of lactation, as well as in the beginning of the grazing period (May) and in August-September. Significant differences between groups were not detected.

The clinical forms of the disease in mastitis in most cases had a chronic course. In most cases, latent mastitis transitions into clinical form. Chronic mastitis in $40 \%$ of cases occurred with atrophy of the affected 
lobe of the udder. After the next calving, the atrophic processes in the trunk remained unchanged. During the study period, there were 2 cases of injury to the udder (trauma of doves) as a result of which the animals left the herd. Cows of group II, who were born in the conditions of permanent exposure to radioactive irradiation, were more often ill with hidden mastitis. During the period of research in both groups against the background of reduction of clinical mastitis, there was an increase in the latent. In 2007, compared to 2004, their number increased by $50 \%$ and $25 \%$. If the ratio of latent mastitis to all cows in group I ("clean" zone), and clinically patients at the beginning of the experiment was $1: 10$ and $1: 6$, then at the end of $1: 4,5$ and $1: 4$. In animals of group II ("polluted" zone), respectively, 1: 6,7 and 1: 5; 1: 3.3 and 1:1.5.

Indicators of reproductive capacity are given in Table 2 . Service period, the animals of both groups are almost the same as the number of inseminints. But such indicators are due to the fact that the animals of group II more exited during the experiment, and they were not taken into account in the calculations.

\section{Service period}

\begin{tabular}{|l|l|l|l|l|l|l|}
\hline \multirow{2}{*}{ Year } & \multicolumn{3}{|l|}{ Group I ("clean" zone) } & \multicolumn{3}{l|}{ Group II ("polluted" zone) } \\
\cline { 2 - 7 } & $\mathbf{n}$ & Service period & Number of inseminans & $\mathbf{n}$ & Service period & $\begin{array}{l}\text { Number } \\
\text { inseminans }\end{array}$ \\
\hline 2004 & 19 & $59,95 \pm 4,26$ & $1,84 \pm 0,12$ & 17 & $57,88 \pm 2,04$ & $1,88 \pm 0,08$ \\
\hline 2005 & 19 & $57,42 \pm 4,45$ & $2,11 \pm 0,17$ & 17 & $56,82 \pm 5,44$ & $1,76 \pm 0,18$ \\
\hline 2006 & 19 & $59 \pm 3,40$ & $1,94 \pm 0,13$ & 17 & $54,07 \pm 3,27$ & $1,77 \pm 0,12$ \\
\hline
\end{tabular}

During the experiment (2004-2007), 9 animals were slaughtered, or $22.5 \%$. The percentage of live animals raised in local conditions was higher and was $15 \%$ for the second year, and $35 \%$ for the fourth year, against $5 \%$ and $10 \%$ for the group of imported animals. Reasons for the elimination of all animals - the problems, to varying degrees, are related to the reproductive function. From the first group (the "clean zone") one animal emerged after the first calving (postpartum complications), the second animal after the third calving (complications of the postnatal period, injury to the udder). In animals of the second group ("polluted zone") 7 animals were eliminated. Three heads (15\%) disappeared after the first calving (postpartum complications), four head (20\%) after the third calving (postpartum complications, injuries to the udder (1 point).

\section{Conclusions}

Thus, the results of the conducted studies indicate that in animals that for a long period of time are under the influence of ionizing radiation of low intensity, blood parameters are on the lower boundary of the norm; throughout the experiment there is a "shift" of neutrophils to the left. Animals brought into the area of radioactive contamination by adults are more stress-resistant in comparison with local individuals, but over the years, this difference almost disappears, and grown in the "contaminated zone" more painful. They more and more suffered from various forms of endometritis and mastitis.

\section{References}

1. Zolotareva NN, Ryabtsev IA The variability of the biochemical status of the populations of mussel grains exposed to the biological effects of radiation on the radiatia, depending on the timing of the habitat on the territories contaminated with radionuclides // Probst. international scientific Conf. "Chernobyl-96" - 1996. P.472

2. Chernobyl catastrophe / Editor-in-Chief, academician of NASU V.G. Barjahtar K .: Scientific thought. $1995-560 \mathrm{p}$. 
3. Ermakova O.V. Morphologically-induced spontaneous glands and adrenal glands of the mammalian diseases in the Chernobyl nuclear power plant // Sb. Tez. international scientific Conf. "Chernobyl-96" 1996. - p.463 ..

4. Alekseeva ${ }^{\circ}$ L.V. Physical reaction of animals on prolonged exposure by small doses / L.V. Alekseeva, E.D. Solonina / Vses. Conf. On the basis of effective doses of ionizing radiations // Tez. Doc. - K. - 1984. p.30-40. [6]

5. Astasheva N.P. Problems in animal husbandry in territories polluted as a result of the accident at the Chernyshev NPP / N.P. Astasheva // Fifth International Scientific and Technical Conference. "Chernobyl 96". - "Results of 10 years of liquidation of the consequences of the Chernobyl accident accident". Collection of essays. - GreenMis. - 1996. - p.14. [13]

6. Priester B.S. Basic agricultural radiobiology / B.S. Paster, N. A. Loschilov, A. F. Nemets, V. A. Poyarkov // 2nd ed. redone and supplement - K.: Harvest, 1991. - $472 p$.

7. Shkurko T.P. The reproduction ability of the Holstein breed cows as a criterion for their adaptation. I T.P.Shkurko // Bulletin of the Institute of Animal Husbandry of the Central Areas of the UAAS: Scientific and Production Edition. - vip.3 - Dnipropetrovsk: Delita, 2008. - P.42-51

8. Babazhina E. B., Methodological bases of evaluation of clinic-morphological indicators of blood of domestic animals / E. B. Babazhina, AV Korobov, SV Wednesday, VP Saprykin /: Tutorial. - M .: LLC "Aquarium-Print", 2007. - 128s: il ..

9. Methodological recommendations on the organization of genetic examination of cattle in farms of the Kiev region / [B. E. Podoba, V. S. Kachura, S. L. Leont'ev and others; Gosaprogroprom of the USSR, Ukr. Scientific research. In-t to play. The case in livestock breeding. - K., 1988. - 33 p.] 